\title{
Empirical research on the service mode of China's scientific fitness demonstration area
}

\author{
Wenqi Xu \\ Economics and Management School, Wuhan Sports University, Wuhan, Hubei, China
}

\begin{abstract}
Continuous improvement on promoting the scientific fitness service system of mass sports is an important measure to implement nationwide fitness strategy; develop sport industry; and promote sport consumption. This study takes the experimental units of scientific fitness demonstration area regulated by General Administration of Sport of China as the study objects. It combines theoretical research and empirical study together and reached the following conclusions: in order to obtain scientific, demonstrative and sustainable fitness demonstration areas, we shall stick to the guidance of our government; introduce marketing operational mechanism; combine the advantages of human capital from institutions of higher learning; and apply the PPP mode operated by the cooperation between government purchasing service and social capital, making it possible to realize the organic combination of public service and private service.
\end{abstract}

Keywords: nationwide fitness strategy; scientific fitness demonstration area; service mode

\section{INTRODUCTION}

In the $12^{\text {th }}$ Five-Year Plan of Sports Development, the General Administration of Sport of China clearly stated that "we shall try hard to improve mass sports development and improve people's livelihood", "transform knowledge popularization, consulting and scientific research products into integrated scientific and fitness service platform for mass sports, and actively establish demonstration areas of scientific fitness so as to further promote the transformation of scientific fitness results" ${ }^{[1]}$. At present, promotion of scientific resident fitness awareness popularization and improvement in scientific fitness service level have become important parts in developing nationwide fitness strategy. However, it is difficult to carry out and sustain the strategy only with the gradual promotion from top to bottom implemented by the government and through the dependence on incomplete organizational network system of nationwide fitness society. By summarizing the mass sports development accomplished in western countries and the experience, success and failure accumulated in the 20-year implementation of our Outline of the Nationwide Fitness Program, we can find that the realistic choice for us is to take full use all social resources and establishing the organizational network connecting resources from government, society and market by building socialized and market-oriented scientific fitness service system, so as to provide reasonable market linkage mechanism and channels of diversified and personalized scientific fitness service for citizens. Thus, middle-end and high-end groups with certain needs and consumption power can enjoy market-oriented service. Besides, it can also offer powerful guarantee of basic public fitness service to vulnerable groups and those with limited consumption power The establishment of scientific fitness service system not only involves the responsibilities of livelihood guarantee taken by the government, but also involves the intersection of public service and market service. It is both a career and an industry with wide coverage. The major problem in accelerating our current mass sports development is how to continue the enhancement on the leading function of the government while promoting innovation and reform in our mass sports mechanism; accurately positioning the boundary between scientific public fitness service and market service; establishing financing channels for social capitals to enter nationwide fitness area; cultivating diversified participants; and forming a new pattern for divided cooperation among government, society and market, mutual promotion of career and industry, and interactive development of public service and market 
service in the meantime ${ }^{[2][3]}$.

This thesis uses theoretical study and empirical research in combination to study the significance, connotation, features, and service mode of establishing scientific fitness demonstration areas. It conducts comprehensive analytical research by means of document literature reference, expert interviews, and field research. It plans to conclude the significance connotation and practical experience of establishing scientific fitness demonstration areas in China, so as to provide related proofs for further study and establishment.

\section{CONCEPTUAL DEFINITION AND FEATURES OF "SCIENTIFIC FITNESS DEMONSTRATION AREA"}

\subsection{Conceptual definition}

With increasing investment in nationwide fitness area put by Ministry of Science and Technology and the General Administration of Sport of China, how to transform a large batch of creative results has become a major problem in the technical are in our nationwide fitness program. For this end, the General Administration of Sport of China launched the establishment of scientific fitness area in May, 2013; and selected five different kinds of areas (enterprise and public institution, school, village and town, country, and city) in five cities (including Wuxi, Wuhan, and China Institute of Atomic Energy) as the first test units. According to the explanation given in the $12^{\text {th }}$ Five-Year Plan of Sports Development, "scientific fitness demonstration area" refers to promote the masses' scientific fitness awareness and scientific fitness level according to their needs in scientific fitness; and establish diversified scientific fitness demonstration areas integrated with scientific fitness consulting, knowledge popularization and result transformation relying on the support from rural governments, communities, schools, and large-scale enterprises and public institutions, so as to effectively provide scientific and technical guarantee for implementing the policy of "benefiting the people through scientific technology" and establishing "nationwide fitness public service system", and to reach the goal of improving nationwide scientific fitness level [4]. The proposal of "scientific fitness demonstration area" is the objective reflection of development in current economic society and sport industry. Taking sport as the significant symbol of social economy development is an important presentation of improving our comprehensive national strength and social civilization level.

\subsection{Feature analysis}

Based on the description of scientific fitness demonstration area positioning, the features can be divided into three points as follows:

Scientific: for individuals, sport exercise can be a double-ended sword. Plenty sport medicine studies have proved that sport exercise can bring us strong and healthy body while keeping us sound in body and mind under reasonable conditions. However, various sport injuries, or even "exercise sudden death", may occur in unreasonable conditions. Thus, the scientific and technical means applied in those scientific fitness demonstration areas need to guarantee the safety of resident's participation in sport exercise; and should also make sure the services, including fitness check, exercise prescription, and fitness guidance, are "effective", "reliable" and "practicable".

Demonstrative: "demonstrative" feature means the demonstration areas shall set good examples or models for people to learn from. It requires that the management mechanism, operating mechanism, service process, and technical means applied in "scientific fitness demonstration areas" should be "scientific" and "advanced". Besides, they should also be able to meet the resident's needs in sport exercise in a practical and realistic way, so as to generate excellent demonstration effect and popularization value.

Sustainable: "Sustainable development" is a key national development strategy. The connotation contained in sustainable development is to satisfy contemporary people's requirements while maintaining the capabilities to protect future generations' benefits. It is part of the basic content in "Scientific Outlook on Development". The establishment of "scientific fitness demonstration area" should fully consider the differences of living conditions in rural areas and urban areas, especially the differences of awareness in sport exercise. It should maintain, make reasonable use of, or improve current "hardware" conditions; and take effective measures and technical means to improve the "software" conditions, so as to make sure the residents in the demonstration areas can continuously enjoy the latest scientific and technological achievements and services from mass sports development.

\section{RESEARCH AND ANALYSIS OF THE SERVICE MODE OF SCIENTIFIC FITNESS DEMONSTRATION AREA}

In May, 2013, the General Administration of Sport of China officially announced the launch of scientific fitness demonstration area establishment in national range. After tracking investigation and empirical research conducted for 2 years, this thesis has concluded three representative modes as shown in Table 1.

\subsection{Analysis of "Government + Scientific Research Unit" service mode--take Wuxi as an example}


Table 1 Construction patterns and features of scientific fitness demonstration area (Wuhan, Wuxi, and CIAE)

\begin{tabular}{|c|c|}
\hline Construction mode & Specific feature \\
\hline $\begin{array}{l}\text { Government }+ \text { scientific research unit } \\
\text { (Wuxi) }\end{array}$ & $\begin{array}{l}\text { This mode is dominated by government with cooperative pattern in combination } \\
\text { of intellectual resources and technical advantages from scientific research unit. }\end{array}$ \\
\hline $\begin{array}{l}\text { Government }+ \text { unit }+ \text { scientific research unit } \\
\text { (CIAE) }\end{array}$ & $\begin{array}{l}\text { This mode is in joint investment made by government and unit and has support } \\
\text { from qualified enterprises and schools for hardware construction. The manage- } \\
\text { ment is jointly implemented by related departments (such as labor union) and } \\
\text { social organizations or scientific research units. }\end{array}$ \\
\hline $\begin{array}{l}\text { Government }+ \text { enterprise }+ \text { scientific research unit } \\
\text { (Wuhan) }\end{array}$ & $\begin{array}{l}\text { In this mode, public service and market service are combined in government } \\
\text { purchasing. In this mode, enterprise takes the role in integrating superior re- } \\
\text { sources from governmental administration, enterprise, and scientific research } \\
\text { unit in market operation and scientific management. }\end{array}$ \\
\hline
\end{tabular}

Table 2 Introduction to the scientific fitness service mode in Wuxi

\begin{tabular}{|c|c|}
\hline Main work & Content outline \\
\hline $\begin{array}{l}\text { Scientific fitness quality inves- } \\
\text { tigation }\end{array}$ & $\begin{array}{l}\text { Fully master community resident's exercise situation and fitness requirements by conduction field } \\
\text { interviews and organizing forums, in order to provide proofs for establishing resident health record, } \\
\text { organizing scientific fitness lectures, and popularizing scientific fitness methods. }\end{array}$ \\
\hline WiFi coverage & $\begin{array}{l}63 \text { fitness sites have bene covered by WiFi network. Scientific fitness information can be delivered } \\
\text { through WiFi and residents have free network access to obtain all the information through mobile } \\
\text { terminals. }\end{array}$ \\
\hline $\begin{array}{l}\text { Interactive platform of scientific } \\
\text { fitness }\end{array}$ & $\begin{array}{l}\text { Launch of scientific fitness service client end App in mobile terminals can provide an interactive } \\
\text { scientific fitness platform for residents, so as to make it convenient for them to check physical } \\
\text { health records and obtain expert inquiry service. }\end{array}$ \\
\hline "Internet + " fitness center & $\begin{array}{l}\text { Create "Internet +" fitness center integrated with fitness and health monitoring, equipment training, } \\
\text { and remote fitness guidance service, so as to realize real-time monitoring, analysis, and guidance } \\
\text { for exerciser's physical test and fitness activities when "no one is on duty". }\end{array}$ \\
\hline $\begin{array}{l}\text { Remote monitoring and man- } \\
\text { agement on fitness facilities }\end{array}$ & $\begin{array}{l}\text { Attach two-dimension codes of information about fitness center and equipment on outdoor fitness } \\
\text { facilities. By scanning the codes on client mobile terminal, users can complete routing facility } \\
\text { inspection and repair requests as well as related feedback. }\end{array}$ \\
\hline Crow traffic monitoring & Set up recognition systems in related places to complete real-time monitoring on crowd traffic. \\
\hline Scientific fitness activities & $\begin{array}{l}\text { Conduct offline activities, such as physical tests, scientific fitness lectures, and fitness network } \\
\text { competitions. }\end{array}$ \\
\hline Resources integration & $\begin{array}{l}\text { Actively apply for various scientific and technological programs and engineering projects by mak- } \\
\text { ing use of technical advantages and combing the capabilities of related organizations, so as to } \\
\text { provide more powerful resources for program construction. }\end{array}$ \\
\hline
\end{tabular}

As one of the scientific fitness demonstration areas, Wuxi is responsible for the study and construction on experimental unit in "urban community" class. Till now, the program has been listed as the Construction of Jiangsu Public Sport Service System Demonstration Area; and has been integrated into The Action Plan of Establishing Jiangsu Public Sport Service System Demonstration Area. With the guidance given from the General Administration of Sport of China and the project team, the Sports Bureau of Wuxi has made full use of its first mover advantages in the new generation of information technology, such as Internet of Things, informatization, and e-commerce. It has combined the actual needs in local fitness development and used advanced technological means in nationwide fitness industry, such as Internet of Things and cloud computing. By improving national physical examination, conducting remote monitoring and management on public sport facilities, completing reform in Internet of Thing for traditional fitness centers, and developing and applying mobile client end App, Wuxi has made great effort to realize series connection of nationwide fitness resources and make preliminary exploration on the mode of "intelligent fitness center, intelligent guidance and intelligent supervision". According to the construction experience accumulated in Wuxi scientific fitness demonstration area, the involved work can be concluded in Table 2 .

After the two years of scientific fitness demonstration area, Wuxi has obtained certain experience in constructing diversified public sport service system and enriching the supply mode of public sport facilities.

(1) Significant improvement in scientific fitness awareness

Under the conceptual guidance of "dual driving from technical guidance and health effect", popularization of scientific fitness common sense should be carried out for people with little regular exercise. According to the diversified requirements asked by people with regular exercise, goals shall be set to improve the cognition degree, participation, and scientization level of scientific fitness and solve resident's dissatisfaction 
in fitness test, hidden safety danger existing in equipment fitness, and shortage of fitness guidance service to a certain degree.

(2) Preliminary accomplishment of convenient and highly efficient remote fitness guidance service

Residents are able to enjoy expert's remote service through mobile client terminal App due to the internet reform in traditional sport facilities and construction of mobile interaction platform. Various professional scientific fitness services are provided for residents in combination of online and offline activities.

(3) Effective reduction in basic public service cost in nationwide fitness

All the sections of traditional nationwide fitness service are all completed by manpower which requires for massive manpower, material resources, and financial resources. By applying Internet of Things, the required fees can be reduced by at least one third compared with that in traditional implementation scheme. What's more important is the new scheme can significantly reduce manpower participation while improving service standardization.

\section{2 "Government + Unit + Scientific Research Unit" mode--take CIAE as an example}

In June, 2013, as the only large-scale enterprise and public institution in nationwide "scientific fitness demonstration area" construction units and with the joint guidance from the General Administration of Sport of China and Beijing Sport University, CIAE has popularized knowledge and new methods of scientific fitness closely according to people's needs in scientific fitness. It has set "serving for personnel health, constructing harmonious institution, popularizing fitness experience, and uniting employee teams" as the goals; and has given full play to the platform function of "scientific fitness demonstration area". CIAE is trying to provide practical service for people; enhance people's scientific fitness awareness; improve people's scientific fitness level; and create atmosphere of "happy work and healthy life".

According to the actual situation and realistic needs in the two areas and three groups of CIAE (south area of working area and north area of living area; active employee group, retired employee group and resident group), CIAE has turned scientific fitness consulting, knowledge popularization, and corresponding results into integrated diversified scientific fitness demonstration area, striving to add affinity in the scientific fitness activities of China National Nuclear Corporation; drive the scientific fitness activities in stagnation zone; and bring benefit to the service system for employee's health (as shown in Table 3).

It can be seen from Table 3 that as an experiment unit in the "enterprise and public institution" class of scientific fitness demonstration area, CIAE has not only made full use of its advantages in management efficiency integration; but has also united its intellectual resources and professional advantages. By constructing fitness facilities and conducting rich and colorful scientific fitness activities, CIAE is trying to meet the diversified fitness requirements for various groups.

\section{3 "Government + Enterprise + Scientific Research Unit" mode--take Wuhan as an example}

In August, 2013, based on consultation and suggestions from various sides and sufficient project assessment, planning and site selection in earlier stage, $\mathrm{Wu}-$ han proposed to construct urban community fitness service center--“Jiangcheng Fitness e Home". It formulated and published Notice of the Implementation Suggestion of "Jiangcheng Fitness e Home" Construction and Management (Trial Implementation). "Jiangcheng Fitness e Home" is a "Five-in-One" (as shown in Figure 1) community scientific fitness service center in combination of fitness test, fitness guidance, popularization and education, health man-

Table 3 Construction Idea and Content of the ' 11151 ' service mode in CIAE

\begin{tabular}{|c|c|}
\hline Construction idea & Content outline \\
\hline " 1 " activity organizing system & $\begin{array}{l}\text { Construct "Two-Community-and-Three-Group" organizing system to give full play to the } \\
\text { key roles of employee's sport federation, employee's art troupe, and retired employee's } \\
\text { literary association and organization, and literary organization of neighborhood committee. }\end{array}$ \\
\hline '1" activity plan & $\begin{array}{l}\text { Conduct questionnaire surveys; organize training activities to popularize scientific fitness } \\
\text { methods and fitness knowledge; arrange fitness check for retired employees; establish hiking } \\
\text { association; organize hiking activities; and improve scientific fitness sites. }\end{array}$ \\
\hline "1" guarantee condition & $\begin{array}{l}\text { Fully arrange fund, area and equipment resources of CIAE in China National Nuclear Cor- } \\
\text { poration and stagnation zones. Establish the mechanism of "joint construction, joint creation } \\
\text { and joint sharing". }\end{array}$ \\
\hline " 5 " general investigations on fitness & $\begin{array}{l}\text { Conduct questionnaire surveys on scientific fitness; organize fitness check and keep records; } \\
\text { arrange training and exhibition popularization of scientific fitness methods; and create sci- } \\
\text { entific fitness atmosphere (showcase, evening party, special column, panting album, and } \\
\text { experience exchange). }\end{array}$ \\
\hline " 1 " harmonious institution & $\begin{array}{l}\text { Enhance people's awareness of scientific fitness; popularize experience of scientific fitness; } \\
\text { improve people's scientific fitness level; unite employee teams; and create harmonious } \\
\text { institution full of "happy work and healthy life". }\end{array}$ \\
\hline
\end{tabular}


agement, and consulting function established under the concept of "introducing market mechanism and government purchasing service, highlighting public benefit orientation, and providing public benefit of resident fitness". The equipment and facilities used in "Jiangcheng Fitness e Home" are provided by governmental sports department. Communities can offer sites and other ancillary facilities according to their conditions; and can authorize professional sports company to be in charge of market-oriented operation mode ${ }^{[6]}$.

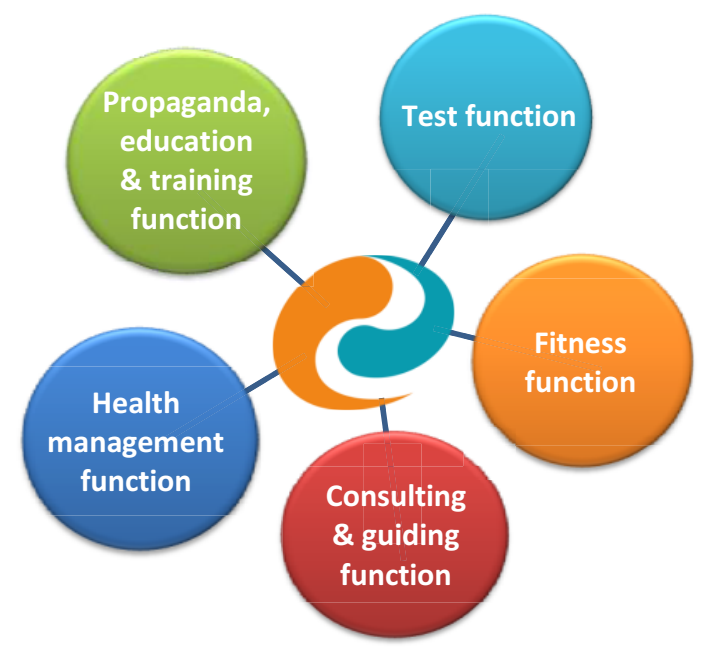

Figure 1. 'Five-in-One' service mode of Jiangcheng Fitness e Home

Its market-oriented operation while the key part of its operation is the sustainability of the mode which is the effective combination of scientific research on nationwide fitness and market requirements. The main features of "Jiangcheng Fitness e Home" can be concluded as follows:

(1) Replicable and sustainable scientific fitness service system

"Jiangcheng Fitness e Home" can integrate all the superior resources of government, society and market, realize the organic combination of public sports service and market service, and solve current insufficiency in public scientific fitness service supply close according to the market requirements in scientific fitness market.

(2) Serving for market requirements

As a commonweal project to bring benefit to all residents, "Jiangcheng Fitness e Home" can guide all residents to participate in scientific fitness under the service concept of "One Yuan per Day". Based on meeting community resident's fundamental fitness requirements, "Jiangcheng Fitness e Home" can provide more than ten value-added services, such as body component, bone mineral density, vascular function, and sub-health. Meanwhile, it can also provide indoor badminton, ping-pong, health maintenance and rehabilitation, leisure tea house, children's outdoor wading pool, children's training and other services in accordance with various community conditions.

(3) Multiple-subject participation mechanism dominated by government

Government, enterprise, and NGO (non-governmental organization) are the three main pillars which are necessary in modern society. In order to solve the paradox between increasing requirements in nationwide fitness and the limited supply from government, the subject scope must be expanded while more diversified subject combination shall be realized. The insufficient situation caused by the sole and direct service supply from government shall be changed. A mode which is dominated by government and widely participated by market, the public and social organizations shall be established by giving full play to functions of market and society.

(4) Establishment of scientific fitness cloud data platform

The most significant feature of "Jiangcheng Fitness e Home" lies in its application of modern information technology and technical means of Internet of Things to implement subject operation. By establishing scientific fitness management system, cloud data platform, personalized information carrier, and management system of customized push service, "Jiangcheng Fitness e Home" can keep a set of complete electronic health records in series for community residents; and can also conduct regular continuous monitoring and physical check in a long term, so as to provide real-time supervision and feedback for community resident's health assessment.

(5) Realization of sustainable market-oriented operation development

"Jiangcheng Fitness e Home" relies on the resources of governmental sports department, community, and market. The advantages of its application in the market-oriented operation mechanism combining market-oriented service and public service are as follows: 1. this mechanism can give full play to the function of market, so as to complete effective allocation of various resources. 2. This mechanism can offer effective popularization about scientific fitness and bring demonstration effect. 3. This mechanism can take full use of market initiative to make market service and products more personalized and closer to people. 4 . This mechanism can provide various personalized and diversified payable services to satisfy requirements from groups in different levels. 5. This mechanism can reduce the cost of government purchasing public service through well-organized market competition.

\section{CONCLUSIONS}

It has been proved through practice that the market-oriented service mode of "government + enterprise 
+ scientific research unit" can better meet the needs existing in current mass sports industry development. The paradox between insufficient government supply and diversified market needs can be continuously solved by establishing public-private partnership and application of government purchasing of public services through franchise, trusteeship, and lease. ${ }^{[6]}$

From the full use of "Internet+" information technology, transform and updating in traditional service means, and platform establishment of sport equipment, internet of facility and data interaction, citizens can easily enjoy expert's personalized service through mobile terminals.

Integration of nationwide fitness and resident's healthcare card can be tried in areas with better economic conditions. When healthcare card balance reaches certain amount, money can be taken in a certain proportion from the card to buy scientific fitness service in areas designated by the government. Although some areas have already made such try, they are still limited by administrative obstruction and other institutional obstacles.

It can be seen from the achievement obtained in the construction of scientific fitness demonstration area that the major part of permanent resident population in villages, towns and rural areas are made up of middle-aged and elder people, children, and juveniles. As middle-aged and elder people are faced on heavy household duties and farm work and there's relative shortage in infrastructure, organizational guarantee, and expenditure support, it is very hard for those people to participate in fitness exercise. Thus, there's still a long way ahead to improve the scientific fitness level and guarantee capability in our villages, towns, and rural areas.

\section{ACKNOWLEDGEMENT}

This paper is supported by the Key Research Area Project of General Administration of Sport of China (No. 2013B039).

\section{REFERENCES}

[1] The 12th Five-Year Plan of Sports Development. [OL]. http://www.sport.gov.cn/n16/n1007/n1467/n1843577/184 3747.html.

[2] Bao, M.X. Promote the Synergetic Development of Mass Sports and Sport Industry--Interpretation of the (No.46) State Council Document [EB/OL]. http://sports.163.com/15/0207/11/AHRKE6LG0005227 R.html.

[3] Several Advices from the State Council on Accelerating the Development of Sport Industry and Promoting Sport Consumption[OL]. http://www.gov.cn/xinwen/2014-10/20/content_2767791 .htm.

[4] Xu, W.Q. \& Chen, L. X. 2015. Practical exploration and inspiration on constructing community scientific fitness service complex in Wuhan. Wuhan Institute of Physical Education, (05): 45-50.

[5] Tian, Y. 2014. Physical activities, constitution and health: 10-year review on nationwide fitness and health promotion. Progress in Physiological Science, (45)4: 243-246.

[6] Wang, C.H. 2015. Theoretical Research on Government Purchasing of Public Services. Beijing: Economic Science Press. 